\title{
Role of Color Doppler in predicting perinatal outcome in preeclampsia
}

\author{
Anjuri J. Roy*, Archana A. Bhosale
}

Department of Obstetrics and Gynecology, Lokmanya Tilak Municipal Medical College and General Hospital, Mumbai, Maharashtra, India

Received: 11 December 2017

Accepted: 08 January 2018

\section{*Correspondence:}

Dr. Anjuri J. Roy,

E-mail: anjuri.roy@gmail.com

Copyright: () the author(s), publisher and licensee Medip Academy. This is an open-access article distributed under the terms of the Creative Commons Attribution Non-Commercial License, which permits unrestricted non-commercial use, distribution, and reproduction in any medium, provided the original work is properly cited.

\section{ABSTRACT}

Background: Preeclampsia is one of the most common complications of pregnancy, which increases both fetal and maternal mortality and morbidity. Since preeclampsia is characterized by abnormal placenta formation leading to inadequate uteroplacental blood flow, Doppler ultrasonography can prove to be a useful tool to assess fetal outcome in PIH patients. Through this study, we sought to determine the perinatal outcome on the basis of Doppler changes seen in Umbilical and Middle Cerebral artery.

Methods: This was a prospective study conducted from September 2014 to August 2017 in a tertiary care hospital where 150 singleton pregnant patients with preeclampsia were examined with Doppler ultrasound of the Umbilical artery and Middle cerebral Artery. Serial Doppler examination was performed and the results of the last Doppler examination within 10 days of delivery was considered. Perinatal outcome was studied in the form of perinatal death, mean APGAR at 1 and 5 minutes, birth weight and admission to Neonatal Intensive Care Unit (NICU).

Results: Abnormal Doppler velocimetry of the umbilical artery (increased resistance, AEDV, REDV) were significantly associated with poor perinatal outcome in the form of low birth weight, APGAR of $\leq 7$ at five minutes of birth and NICU admission. However, S/D ratio of the Middle cerebral artery could not positively predict poor perinatal outcome in this study.

Conclusions: Doppler technology has provided the best opportunity for repetitive non-invasive hemodynamic monitoring in human pregnancy. Umbilical artery Doppler findings are slight better predictor of adverse perinatal outcome than an abnormal MCA.

Keywords: Doppler, Preeclampsia, Perinatal outcome, Umbilical artery

\section{INTRODUCTION}

Preeclampsia is one of the most common medical complications of pregnancy. It is a major cause of maternal and perinatal mortality and morbidity worldwide. ${ }^{1}$ The sole curative treatment for Preeclampsia being delivery, management must counterbalance the risk-benefit ratio of induced preterm delivery and maternal-fetal outcome.

Pre-eclampsia has a complex pathophysiology, the primary cause being abnormal placentation. Defective invasion of the spiral arteries by cytotrophoblast cells prevents spiral arteries from getting converted into low resistance vessels. $^{2}$

Increased uterine arterial resistance induces higher sensitivity to vasoconstriction and thus chronic placental ischemia and oxidative stress. This chronic placental ischemia causes fetal complications.

Since preeclampsia is characterized by inadequate uteroplacental blood flow, Doppler ultrasonography can prove to be a used to assess fetal outcome in 
preeclampsia patients. It is based on the "Doppler principle" that detects changes in frequency occurring when an ultrasound beam strikes a moving object. ${ }^{3}$

Doppler ultrasound provides information regarding three aspects of blood flow - velocity, resistance to blood flow through a particular vessel, volume of blood flow. While the Doppler pattern of the uterine arteries reflects the efficiency of placentation, the Umbilical artery Doppler reflects placental function and indicates degree of placental insufficiency. ${ }^{4,5}$ Cerebral vasodilatation also known as "brain sparing effect" is a response of foetus to chronic hypoxemia by vasoconstriction of somatic, renal and hepatic vessels and increased blood supply to vital organs like brain, heart. This preferential blood flow to brain can be detected by MCA (Middle cerebral artery) Doppler. $^{6}$

In clinical studies, vessels with relatively high diastolic flow velocities are believed to reflect a low downstream impedance to flow and those with low diastolic velocities reflect high impedance. In this way, all the most commonly used indices; S/D ratio, PI (Pulsatility Index), RI (Resistance Index) provide a semi quantitative assessment of impedance in the vessels interrogated.

Altogether, Doppler ultrasound helps one to identify the fetuses at risk and time the delivery. The timely diagnosis of fetal compromise is important so that delivery can be affected before fetus suffers irreversible damage and dies in utero. Doppler does correlate well with fetal compromise giving earlier warning signs of fetal distress than other tests.

Through this study, we sought to determine the perinatal outcome on the basis of Doppler changes seen in Umbilical and Middle Cerebral artery.

\section{METHODS}

This is an analytical study conducted from September 2014 to August 2016 at a tertiary center. 150 consecutive singleton pregnant patients diagnosed with Preeclampsia beyond 34 weeks of gestation were included in the study. Patients with other medical complications in pregnancy, fetuses with congenital anomalies and those who presented for the first time in labor were excluded from the study.

They were examined with pulsed Doppler ultrasound (Toshiba XARIO color Doppler diagnostic system with curvilinear probe of $3.5 \mathrm{MHz}$ ). Gestational age determination was done based on LMP (Last Menstrual Period) or Fetal biometry preferably in first trimester.

The following vessels were studied with the mother in a recumbent position:

- Umbilical Artery (UA)

- $\quad$ Middle Cerebral Artery (MCA)
The above vessels were located in the standard plane:

- The umbilical artery measurements were made from free loop of cord midway between the placental and abdominal wall insertion.

- The middle cerebral artery was located in a transverse plane at the level of the lesser wing of the sphenoid bone with sample gate placed on proximal portion of the vessel.

Systolic/diastolic ratio (S/D) of umbilical artery, middle cerebral artery was noted. These values were considered abnormal when they lie beyond the 5th and 95th percentile for gestational age. Similarly, absence/reversal of end diastolic flow in umbilical artery was also noted. The patients were subjected to Doppler ultrasound weekly. The results of the last Doppler examination within 10 days of delivery were considered.

Neonatal outcome was assessed depending on

- $\quad$ Birth weight

- Apgar at 5 minutes

- Requirement of NICU care

- Duration of NICU stay

- Perinatal Mortality

\section{Statistical analysis}

The information collected was analyzed using the statistical package for the social sciences software (SPSS) version 20.0. The qualitative data was represented as frequency or percentage, bar diagrams and pie charts and quantitative data was presented with the help of mean and standard deviation. The association between two qualitative data was analyzed by Chi Square test and the ' $p$ ' value less than 0.05 was considered significant and Fischer exact test if the cell value was less than 5 in a $2 \times 2$ cross table.

\section{RESULTS}

$51.3 \%$ patients in the study group fall in the age group of 18-24 years.

Table 1: Age distribution.

\begin{tabular}{|l|l|l|}
\hline Age group & Frequency & Percent \\
\hline $18-24$ years & 77 & 51.3 \\
\hline $25-30$ years & 65 & 43.3 \\
\hline$>30$ years & 8 & 5.3 \\
\hline Total & 150 & 100.0 \\
\hline
\end{tabular}

Table 2: Gravidity.

\begin{tabular}{|lll|}
\hline Gravidity & Frequency & Percent \\
\hline Primigravida & 82 & 54.7 \\
\hline Multigravida & 68 & 45.3 \\
\hline Total & 150 & 100.0 \\
\hline
\end{tabular}


Majority of the patients in the study group were primigravida. Preeclampsia is known to be more common in primigravida.

Table 3: Severity of preeclampsia.

\begin{tabular}{|lll|}
\hline Preeclampsia & Frequency & Percent \\
\hline Mild & 120 & 80.0 \\
\hline Severe & 30 & 20.0 \\
\hline Total & 150 & 100.0 \\
\hline
\end{tabular}

Majority of patients had mild preeclampsia whereas only $20 \%$ patients had severe preeclampsia.

Table 4: Gestational age at delivery.

\begin{tabular}{|c|c|c|}
\hline & Frequency & Percent \\
\hline 34- 36.6 weeks & 50 & 33.3 \\
\hline 37- 39.6 weeks & 97 & 64.7 \\
\hline 40 weeks onwards & 3 & 2 \\
\hline Total & 150 & 100 \\
\hline
\end{tabular}

Around $67 \%$ patients were delivered at term i.e. after 37 weeks of gestation. 50 patients were delivered before 37 completed weeks of gestation.

In these patients, pregnancy was terminated in 21 patients due to abnormal Doppler changes, 9 patients due to severe uncontrolled Preeclampsia, 6 patients due to severe oligohydramnios, 2 patients due to PPROM. Labor was spontaneous in onset in the remaining 12 patients who delivered before 37 completed weeks.

Table 5: Doppler velocimetry of umbilical artery (s/d ratio).

\begin{tabular}{|lll|}
\hline S/D OF Umbilical artery & Frequency & Percent \\
\hline Normal & 65 & 43.3 \\
\hline Increased resistance & 69 & 46.0 \\
\hline AEDV & 10 & 6.7 \\
\hline REDV & 6 & 4.0 \\
\hline Total & 150 & 100.0 \\
\hline
\end{tabular}

Out of 150 patients of preeclampsia, 69 patients showed abnormal Doppler velocity waveforms in the form of increased resistance in the umbilical artery.

In addition, 10 patients showed absent end-diastolic flow and 6 patients showed reversal of end-diastolic flow.

Table 6: Doppler velocimetry of middle cerebral $\operatorname{artery}(\mathrm{S} / \mathrm{D}$ ratio).

\begin{tabular}{|lll|}
\hline S/D OF MCA group & Frequency & Percent \\
\hline Normal & 124 & 82.7 \\
\hline Abnormal & 26 & 17.3 \\
\hline Total & 150 & 100.0 \\
\hline
\end{tabular}

Out of the 150 preeclamptic patients, only 26 patient showed abnormalities in the $\mathrm{S} / \mathrm{D}$ ratio of the Middle Cerebral Artery waveforms.

Table 7: Mode of delivery.

\begin{tabular}{|lll|}
\hline Mode of delivery & Frequency & Percent \\
\hline Caesarean section & 63 & 42.0 \\
\hline Vaginal induced & 45 & 30.0 \\
\hline Vaginal spontaneous & 42 & 28.0 \\
\hline Total & 150 & 100.0 \\
\hline
\end{tabular}

42\% patients underwent Caesarean Section while 30\% patients were induced with PGE2 gel and delivered vaginally. Labour was spontaneous in onset in the remaining $28 \%$ patients.

\section{Table 8: Indication for caesarean section.}

\begin{tabular}{|ll|}
\hline Indication for caesarean section & Frequency \\
\hline Severe preeclampsia & 9 \\
\hline Doppler changes & 45 \\
\hline Failed induction/ poor Bishop's score & 10 \\
\hline Severe oligohydramnios & 11 \\
\hline MSAF & 19 \\
\hline Fetal distress & 10 \\
\hline
\end{tabular}

In present study, LSCS was done in 63 preeclamptic patients. The main indications were Doppler changes in 45 patients, meconium stained amniotic fluid in 19 patients, severe oligohydramnios in 11 patients, fetal distress or non-reassuring fetal heart rate patterns in 10 patients and severe preeclampsia in 9 patients.

Table 9: Poor perinatal outcome.

\begin{tabular}{|lll|}
\hline Outcome & Frequency & Percent \\
\hline Birth Weight $<2.5 \mathrm{~kg}$ & 75 & 50.0 \\
\hline APGAR at 5 minutes $\leq 7$ & 74 & 49.3 \\
\hline Need for NICU admission & 77 & 53.1 \\
\hline Perinatal Mortality & 14 & 9.33 \\
\hline
\end{tabular}

In present study, $50 \%$ patients were less than $2.5 \mathrm{~kg}$. $49.3 \%$ of babies had an APGAR of $\leq 7$ at 5 minutes of birth. $77 \%$ needed NICU admission.

Five still births occurred in the study. One was associated with increased resistance in the umbilical artery, one was associated with REDV and the remaining three with AEDV. Pregnancy could not be terminated earlier in these patients as the fetuses were extremely growth restricted and the fetal weight was less than $1000 \mathrm{~g}$.

Nine neonatal deaths occurred in the study. Two of these occurred with increased resistance in umbilical artery alone, two with increased resistance in umbilical artery plus abnormal S/D ratio in middle cerebral artery, two with AEDV and two with REDV. One still birth occurred 
with normal Doppler velocimetry due to meconium aspiration syndrome.

Table 10: Association between abnormal doppler velocimetry of S/D ratio of umbilical artery and MCA with low birth weight.

\begin{tabular}{|c|c|c|c|}
\hline \multirow{2}{*}{ Doppler results } & \multicolumn{2}{|c|}{ Birth weight } & \multirow{2}{*}{ P value } \\
\hline & $>2.5 \mathrm{~kg}$ & $<2.5 \mathrm{~kg}$ & \\
\hline $\begin{array}{l}\text { Increased resistance } \\
\text { in umbilical artery }\end{array}$ & $\begin{array}{l}25 \\
(36.2 \%)\end{array}$ & $\begin{array}{l}44 \\
(63.8 \%)\end{array}$ & $\begin{array}{l}0.03 \\
\text { significant }\end{array}$ \\
\hline $\begin{array}{l}\text { AEDV in umbilical } \\
\text { artery }\end{array}$ & $0(0 \%)$ & $\begin{array}{l}10 \\
(100 \%)\end{array}$ & $\begin{array}{l}0.01 \\
\text { significant }\end{array}$ \\
\hline $\begin{array}{l}\text { REDV in umbilical } \\
\text { artery }\end{array}$ & $0(0 \%)$ & $\begin{array}{l}6 \\
(100 \%)\end{array}$ & $\begin{array}{l}0.028 \\
\text { significant }\end{array}$ \\
\hline Abnormal MCA & $\begin{array}{l}14 \\
(53.8 \%)\end{array}$ & $\begin{array}{l}12 \\
(45.2 \%)\end{array}$ & $\begin{array}{l}0.830 \text { not } \\
\text { significant }\end{array}$ \\
\hline
\end{tabular}

44 out of 69 neonates $(63.8 \%)$ with increased resistance in the Umbilical artery were low birth weight as compared to 31 out of 91 neonates $(38.3 \%)$ with normal umbilical artery Doppler who were low birth weight. Using the Chi Square test, this difference was found to be significant. All neonates with AEDV and REDV had birth weight less than $2.5 \mathrm{~kg}$.

12 out of 26 neonates (45.2\%) with abnormal S/D ratio of MCA were low birth weight as compared to 63 out of 124 neonates $(50.8 \%)$ with normal umbilical artery Doppler who were low birth weight. Using the Chi Square test, this difference was not found to be significant.

Table 11: Association between abnormal Doppler velocimetry of S/D ratio of umbilical artery and MCA with poor APGAR score.

\begin{tabular}{|llll|}
\hline \multicolumn{4}{|l|}{ APGAR score at 5 } \\
Doppler results \\
$\begin{array}{l}\text { minutes } \\
\leq 7\end{array}$ & $\mathbf{> 7}$ & P value \\
\hline $\begin{array}{l}\text { Increased } \\
\text { resistance in } \\
\text { umbilical artery }\end{array}$ & $\begin{array}{l}42 \\
(60.9 \%)\end{array}$ & $\begin{array}{l}27 \\
(39.1 \%)\end{array}$ & $\begin{array}{l}0.014 \\
\text { significant }\end{array}$ \\
\hline $\begin{array}{l}\text { AEDV in } \\
\text { umbilical artery }\end{array}$ & $9(90 \%)$ & $1(10 \%)$ & $\begin{array}{l}0.009 \\
\text { significant }\end{array}$ \\
\hline $\begin{array}{l}\text { REDV in } \\
\text { umbilical artery }\end{array}$ & $6(100 \%)$ & $0(0 \%)$ & $\begin{array}{l}0.009 \\
\text { significant }\end{array}$ \\
\hline Abnormal MCA & $\begin{array}{l}12 \\
(46.2 \%)\end{array}$ & $\begin{array}{l}14 \\
(53.8 \%)\end{array}$ & $\begin{array}{l}0.830 \text { not } \\
\text { significant }\end{array}$ \\
\hline
\end{tabular}

$60.9 \%$ patients with increased resistance in the Umbilical artery delivered neonates with an APGAR of $\leq 7$ at 5 minutes which was significantly higher than $39.5 \%$ patients with normal umbilical artery Doppler who delivered neonates with an APGAR of $\leq 7$ at 5 minutes.

$46.2 \%$ patients with abnormal S/D ratio of middle cerebral artery delivered neonates with an APGAR of $\leq 7$ at 5 minutes which was not significantly lower than $50 \%$ patients with normal MCA Doppler who delivered neonates with an APGAR of $\leq 7$ at 5 minutes.

Table 12: Association between abnormal Doppler velocimetry of S/D ratio of umbilical artery and M CA with need for NICU admission.

\begin{tabular}{|c|c|c|c|}
\hline \multirow[t]{2}{*}{ Doppler results } & \multicolumn{2}{|c|}{$\begin{array}{l}\text { Need for NICU } \\
\text { admission }\end{array}$} & \multirow[t]{2}{*}{$\mathbf{P}$ value } \\
\hline & Yes & No & \\
\hline $\begin{array}{l}\text { Increased resistance } \\
\text { in umbilical artery }\end{array}$ & $\begin{array}{l}52 \\
(67.5 \%)\end{array}$ & $\begin{array}{l}16 \\
(20.8 \%)\end{array}$ & $\begin{array}{l}0.005 \\
\text { significant }\end{array}$ \\
\hline $\begin{array}{l}\text { AEDV in umbilical } \\
\text { artery }\end{array}$ & $\begin{array}{l}7 \\
(100 \%)\end{array}$ & $0(0 \%)$ & $\begin{array}{l}0.015 \\
\text { significant }\end{array}$ \\
\hline $\begin{array}{l}\text { REDV in umbilical } \\
\text { artery }\end{array}$ & $\begin{array}{l}5 \\
(100 \%)\end{array}$ & $0(0 \%)$ & $\begin{array}{l}0.061 \\
\text { significant }\end{array}$ \\
\hline Abnormal MCA & $\begin{array}{l}13 \\
(50 \%)\end{array}$ & $\begin{array}{l}13 \\
(50 \%)\end{array}$ & $\begin{array}{l}0.726 \text { not } \\
\text { significant }\end{array}$ \\
\hline
\end{tabular}

$61.8 \%$ patients with increased resistance in the Umbilical artery delivered neonates who required NICU admission at birth which was significantly higher than $45.5 \%$ patients with normal umbilical artery Doppler who delivered neonates that required NICU admission.

All patients with AEDV and REDV needed NICU admission.

$50 \%$ patients with abnormal S/D ratio of middle cerebral artery delivered neonates who required NICU admission at birth which was not significantly higher than $46.2 \%$ patients with normal MCA Doppler who delivered neonates that required NICU admission.

\section{DISCUSSION}

Preeclampsia, the hypertensive disorder of pregnancy, is strongly related to development and function of uteroplacental and fetoplacental circulations. This results in improper blood flow in uterine and umbilical arteries. An adequate fetal circulation is necessary for normal fetal growth. To facilitate this, remarkable maternal and placental vasculature changes occur during pregnancy.

In normal pregnancy the 3 indices S/D, PI and RI decreases with advancing gestation in umbilical artery but in IUGR first there is decreased diastolic flow in umbilical artery due to increase in the resistance that occurs in small arteries and arterioles of the tertiary villi. This raises the S/D ratio; PI and RI of umbilical artery. As the placental insufficiency worsens, the diastolic flow decreases, then becomes absent, and later reverses. Fetal MCA is a low resistance circulation throughout pregnancy and accounts for $7 \%$ cardiac output of the fetus. ${ }^{7}$ The MCA seems to react earlier and sensitively to hypoxia and ischemia.

The underlying pathology in pre-eclampsia is faulty placentation and widespread vasoconstriction resulting in endothelial damage. ${ }^{2}$ This affects multiple organs in the 
mother and has a significant impact on the fetus. The main objective of antepartum fetal surveillance in a high risk pregnancy in preeclampsia is to detect compromised fetus to allow timely delivery. Doppler velocimetry study is one such noninvasive tool which can be carried out to prevent adverse perinatal outcome.

\section{Demographic perspectives}

In the present study majority of the patients (51.3\%) belonged to the age group of 18 to 24 years. $43 \%$ patients belonged to the age group of 24 to 30 years and only $5 \%$ patients were more than 30 years of age.

Majority of the patients $(54.7 \%)$ were primigravida. Preeclampsia is known to be more common in primigravida.

In the present study, $80 \%$ patients had mild preeclampsia whereas $20 \%$ had severe preeclampsia.

Among the 150 preeclamptic patients, Caesarean section was done in $42 \%$ cases, $30 \%$ patients were induced and delivered vaginally and remaining $30 \%$ delivered spontaneously and vaginally.

$50 \%$ patients delivered babies that were low birth weight $(<2.5 \mathrm{~kg})$ and $49.3 \%$ had an APGAR score of $\leq 7$ at five minutes of birth. $53 \%$ required NICU admission.

Five still births and nine neonatal deaths occurred in the study.

\section{Umbilical artery Doppler}

Umbilical artery velocimetry correlates with hemodynamic changes in the fetoplacental circulation. With increase in number of tertiary stem villi and arterial channels, fetoplacental compartment develops and the impedance in the umbilical artery decreases. From 15 weeks of gestation umbilical artery resistance declines and the diastolic component appears in the waveform during early second trimester. ${ }^{5} \mathrm{~S} / \mathrm{D}$ ratio of less than or equal to 3 is considered normal.

In the present study, abnormal umbilical artery flow velocity waveforms were seen in 85 patients. Among these 85 preeclamptic patients, 69 had increased resistance to flow, 10 had absent end-diastolic flow and the remaining 6 patients had reversed end-diastolic flow in the umbilical artery.

In patients with increased resistance in umbilical artery Doppler, $49.3 \%$ were delivered by caesarean section whereas $45 \%$ of the patients delivered vaginally after being induced and $5.7 \%$ delivered vaginally and spontaneously. $63.8 \%$ babies had a birth weight of less than $2.5 \mathrm{~kg}$. $60.9 \%$ had an APGAR of $\leq 7$ at 5 minutes of birth. $61.8 \%$ required NICU admission and the average duration of NICU stay was 2.86 days. There was one still birth and 4 neonatal deaths associated with this Doppler change.

In patients with absent end-diastolic flow on umbilical artery Doppler, $70 \%$ were delivered by caesarean section (7 patients) whereas labor was induced in the remaining $30 \%$ of the patients. Of the seven patients that were delivered by caesarean section, two neonatal deaths were observed whereas among the remaining three in whom labor was induced, it was done for IUFD (still birth). All babies with AEDV had a birth weight of less than $2.5 \mathrm{~kg}$. $90 \%$ had an APGAR of $\leq 7$ at 5 minutes of birth. All required NICU admission and the average duration of NICU stay was 5.8 days. There was three still births and 2 neonatal deaths associated with this Doppler change (perinatal mortality $50 \%$ ).

In patients with reversed end-diastolic flow on umbilical artery Doppler (6 patients), there was one still birth. The remaining five patients were delivered by caesarean section. Of the five patients that were delivered by caesarean section, two neonatal deaths were observed. All babies with REDV had a birth weight of less than 2.5 $\mathrm{kg}$. All had an APGAR of $\leq 7$ at 5 minutes of birth and required NICU admission and the average duration of NICU stay was 7 days. There was one still birth and two neonatal deaths associated with this Doppler change (perinatal mortality 50\%).

A strong relationship between the umbilical artery Doppler indices and fetal wellbeing has been demonstrated in several studies. Elevation of umbilical artery Doppler indices in the presence of positive end diastolic flow is associated with hypoxemia at a steady state as shown by Bilardo et al. ${ }^{8}$ Loss of end-diastolic flow in the umbilical artery is associated with significant worsening of hypoxemia and academia may be present.

Yoon et al demonstrated that poor perinatal outcome occurred more frequently in women with an abnormal umbilical artery waveform than those with a normal waveform. $^{9}$ Indeed, the rates of preterm delivery, caesarean section for fetal distress, APGAR score $<7$ at 1 min and five minutes, admission to NICU, occurrence of significant neonatal morbidity and perinatal death were significantly higher in the patients with an abnormal waveform.

In the study conducted by Bhatt et al, $44 \%$ had normal doppler velocimetry whereas $56 \%$ had abnormal S/D ratio in umbilical artery. ${ }^{3} 60 \%$ of these hypertensive patients with abnormal velocimetry delivered babies with poor perinatal outcome in the form of IUGR.

In the study conducted by Lalthantluanga et al on 100 hypertensive patients, fetuses with Umbilical Artery S/D ratio $\geq 3$ had IUGR in $41.40 \%$, Apgar score at 5 minutes in $44.8 \%$ and resulted in NICU admission in $56.90 \% .{ }^{10} \mathrm{In}$ the present study, the incidence of poor perinatal outcome was a little higher in those with umbilical artery increased 
resistance. $63.8 \%$ babies had a birth weight of less than $2.5 \mathrm{~kg} .60 .9 \%$ had an APGAR of $\leq 7$ at 5 minutes of birth. $61.8 \%$ required NICU admission.

Vedaraju KS in his study showed that umbilical artery shows significant correlation with adverse fetal outcomes. $^{11}$

In the present study, in patients with AEDV and REDV perinatal mortality was $50 \%$ and the rest $50 \%$ had poor perinatal outcome. The same was observed by Battaglia et al and Bhatt et al in their studies.

The patients with AEDV in umbilical artery should undergo intensive surveillance and REDV represents a pre-terminal fetal state. Patient with AEDV and REDV has gravest outcome as shown by MC Parkland.

\section{Middle cerebral artery Doppler}

In the present study, abnormal Doppler velocity waveform in the S/D ratio of the middle cerebral artery was seen in 26 patients (17.3\%). 42.3\% patients required caesarean section while induction was done in $57.7 \%$ who delivered vaginally. $46.2 \%$ were low birth weight and the same number had an APGAR of $\leq 7$ at five minutes of birth. $50 \%$ required NICU admission and the average duration of NICU stay was 2.35 days. There was no perinatal mortality seen exclusively with an abnormal MCA S/D ratio Doppler.

Yalti et al stated that fetuses with adverse perinatal outcome had a lower middle cerebral artery S/D ratio. ${ }^{12}$

Vedaraju KS et al showed in his study that fetal MCA Doppler does not show positive correlation with poor perinatal outcome which is consistent with the present study. ${ }^{11}$

Although an increase in cerebral arterial end diastolic flow velocimetry may reflect chronic fetal hypoxemia, there is no evidence that this measurement will provide additional benefit to perinatal outcome beyond the assessment of the umbilical circulation alone.

\section{CONCLUSION}

Preeclampsia during pregnancy is the most common medical condition encountered. Doppler analysis helps not only earlier detection of uteroplacental and fetoplacental changes associated with the disease but also help to take decision for early intervention. Intervention may require to be done in preterm gestation so patient can be referred to higher centre for better NICU facilities which can be decided soon because of abnormal Doppler changes. Also, steroids can be administered for fetal lung maturity to improve perinatal outcome.
Abnormal fetoplacental circulation is more associated with adverse outcome as compared to abnormal uteroplacental circulation.

Umbilical artery Doppler findings are slight better predictor of adverse perinatal outcome than an abnormal MCA. Thus, Doppler ultrasound makes it possible to distinguish between a compensated and decompensated placental insufficiency.

Reduced, absent or reversal of EDV in umbilical artery should prompt the obstetrician for timely intervention and prevent adverse perinatal outcome.

Doppler technology has provided the best opportunity for repetitive non-invasive hemodynamic monitoring in human pregnancy.

Perinatal morbidity and mortality can be reduced by fetal surveillance with Doppler velocimetry study. In this small and preliminary study, we have assessed the role of Doppler ultrasound and found it.

Funding: No funding sources

Conflict of interest: None declared

Ethical approval: The study was approved by the Institutional Ethics Committee

\section{REFERENCES}

1. Zeeman GG, Dekker GA. Pathogenesis of preeclampsia: a hypothesis. Clin Obstet Gynecol. 1992 Jun;35(2):317-37.

2. Brosens IA, Robertson WB, Dixon HG. The role of the spiral arteries in the pathogenesis of preeclampsia. Obstet Gynecol Annu. 1972;1:177-91.

3. Bhatt, Arora J, Shah M. Role of color doppler in pregnancy induced hypertension (a study of 100 cases). Indian J Radiol Imaging. 2003;13(4):417.

4. Thaler I, Manor D, Itskovitz J, Rottem S, Levit N, Timor-Tritsch I et al. Changes in uterine blood flow during human pregnancy. Am J Obstet Gynecol. 1990 Jan;162(1):121-5.

5. Schulman H, Fleischer A, Stern W, Farmakides G, Jagani N, Blattner P. Umbilical velocity wave ratios in human pregnancy. Am J Obstet Gynecol. 1984 Apr;148(7):985-90.

6. Picconi JL, Hanif F, Drennan K, Mari G. The transitional phase of ductus venosus reversed flow in severely premature IUGR fetuses. Am J Perinatol. 2008 Apr;25(4):199-203.

7. Giles WB. Vascular Doppler techniques. Obstetrics and Gynecology Clinics. 1999 Dec 1;26(4):595-606.

8. Bilardo CM, Nicolaides KH, Campbell S. Doppler measurements of fetal and uteroplacental circulations: Relationship with umbilical venous blood gases measured at cordocentesis. Am J Obstet Gynecol. 1990;162(1):115-20.

9. Yoon BH, Lee CM, Kim SW. An abnormal umbilical artery waveform: a strong and independent 
predictor of adverse perinatal outcome in patients with preeclampsia. Am J Obstet Gynecol. 1994 Sep;171(3):713-21.

10. Lalthantluanga C, Devi N, Singh N, Shugeta N, Khuman V, Keishing S. Study on role of obstetrical Doppler in pregnancies with hypertensive disorders of pregnancy. J Med Soc. 2015;29(2):79.

11. Vedaraju KS, Kanakannavar SS. USG Doppler study of uterine, umbilical and foetal middle cerebral arteries among severe pre-eclamptic women and their relation to perinatal outcomes. Int J Anatomy Radiol Surg. 2016;5(2):14-8.
12. Yalti S, Oral O, Gurbuz B, Ozden S, Atar F. Ratio of middle cerebral to umbilical artery blood velocity in preeclamptic and hypertensive women in the prediction of poor perinatal outcome. Indian $\mathrm{J}$ Med Res. 2004 Jul 1;120(1):44.

Cite this article as: Roy AJ, Bhosale AA. Role of Color Doppler in predicting perinatal outcome in preeclampsia. Int J Reprod Contracept Obstet Gynecol 2018;7:652-8. 